dritic composition. On the other hand, it would be unrealistic to suppose that such a simple reaction is applicable to the whole Earth and thus that the oxide-sulphide equilibrium is anything but vaguely indicative of real conditions. This view is supported by the data. For example, sodium can also be seen to possess a high negative free energy of reaction, which fact would suggest that sodium was also withdrawn into the core and correspondingly depleted in the crust. But this is patently not so.

As Goldschmidt pointed out many years ago (in Geochemistry, Clarendon Press, Oxford, 1954), different reactions are applicable to different parts of the Earth. Thus Hall and Murthy go on to consider more appropriate equilibria. For the crust they examine reactions of the type $\mathrm{MeSO}_{4}$ with $\mathrm{FeS}$ and $\mathrm{MeCO}_{3}$ with $\mathrm{FeS}$, which are consistent with the typically high oxidation states of crustal material. By contrast, for the mantle, which at the time of $\mathrm{Fe}-\mathrm{S}$ segregation would have been in a reducing environment, the corresponding reactants with $\mathrm{FeS}$ are of the type $\mathrm{MeSiO}_{3}$ and $\mathrm{Me}_{2} \mathrm{SiO}_{4}$. For each of the seventeen elements and for each reaction Hall and Murthy have computed heats of reaction (which dominate the free energies of reaction).

The results are striking. Elements like $\mathrm{Be}$ and $\mathrm{Th}$ (and thus by implication U) are strongly lithophilic under both crustal and mantle conditions. By contrast, elements such as $\mathrm{Cu}, \mathrm{Hg}, \mathrm{Ag}$, $\mathrm{Pb}$ and $\mathrm{Zn}$ are strongly chalcophilic under crustal conditions and remain so throughout the mantle. But the critical elements $\mathrm{K}, \mathrm{Rb}$ and $\mathrm{Cs}$ which are strongly lithophilic under crustal conditions rapidly change to being chalcophile under mantle conditions. In the presence of an $\mathrm{Fe}-\mathrm{S}$ liquid these elements would thus have been drawn into the liquid and thus into the core. Sodium, on the other hand, remains lithophilic in the primitive mantle-and so the anomaly implied by the oxidesulphide equilibrium disappears. In short, notwithstanding the fact that the reactions considered must be oversimplified compared with those applicable to the real Earth, the thermodynamic data obtained by Hall and Murthy are consistent with known abundances of the relevant alkalis in the crust and mantle.

As Hall and Murthy admit, however, this apparent success conceals some real objections. For example, their calculations have been made for an aluminium-free system; and it is well known that $\mathrm{Na}$ and $\mathrm{K}$ have different terrestrial relationships with A1. Under crustal conditions both $\mathrm{Na}$ and $\mathrm{K}$ form alumino-silicates, especially felspars. But in the mantle, where pressures are higher, felspars are unstable and change to denser phases such as jadeite, the $\mathrm{Na}$ alumino-silicate. Potassium, on the other hand, does not apparently produce a high pressure form equivalent to jadeite for $\mathrm{Na}$. If such a form really cannot exist, that fact alone may account to some extent for the different behaviours of $\mathrm{Na}$ and $\mathrm{K}$ in mantle regions. Ignorance of mantle conditions at the time of core formation precludes any detailed assessment of the role of $\mathrm{Al}$ at present, although, whatever the cause, the difference in behaviour between $\mathrm{Na}$ and $\mathrm{K}$ seems established. And further support for it comes from crystal chemistry. Potassium (and $\mathrm{Cs}$ and $\mathrm{Rb}$ ) ions are larger than $\mathrm{Na}$ (and $\mathrm{Li}$ ) ions and are thus less likely to fit into the mantle pyroxene structure but more likely to be absorbed into an available liquid. Thus Hall and Murthy suggest that "the incompatible nature of $\mathbf{K}, \mathbf{H b}$, and Cs which has been reflected in their selective enrichment into basaltic melts through geological time must also be reflected in their enrichment into an $\mathrm{Fe}-\mathrm{S}$ liquid during core formation in the early history of the Earth".

The distribution of elements implied by the early existence of an Fe-S melt, and, in particular, the removal of $K$ into the core, would, of course, have affected the Earth's thermal historyand this implies that many conventional thermal models of the Earth must be revised. The apparent near-constancy of $\mathrm{K} / \mathrm{U}$ ratios for a variety of terrestrial rocks has led many people to suppose that such a ratio (about $1 \times 10^{4}$ ) is a fixed feature of the Earth, the critical variable being the original total radioactivities in various parts of the Earth. But what Hall and Murthy have done is to show that this assumed "coherence" between $K$ and $U$ is not necessarily valid and that, on the contrary, it is quite possible that $\mathbf{K}$ separated from $U$ (and $T h$ ) during the early history of the Earth.

Finally, the fact that $\mathbf{R b}$ behaves like $\mathrm{K}$ in the presence of an $\mathrm{Fe}-\mathrm{S}$ liquid would explain why $\mathrm{Rb} / \mathrm{Sr}$ ratios in the Earth's crust are lower than chondritic. In short, if Hall and Murthy are right about the presence of an $\mathrm{Fe}-\mathrm{S}$ melt during the early history of the Earth, the principal objections to the chondritic Earth are apparently removed.

\title{
Dynamic Stereochemical Model for ATP Synthesis
}

THERE have been many models of the mechanism by which chloroplasts and mitochondria can utilize redox energy associated with electron flow for photo and oxidative phosphorylation. In recent years the chemiosmotic scheme and chemical hypothesis (see Greville in Current Topics in Bioenergetics (edited by D. R. Sanadi, 3, Academic Press, New York and London, 1969) have commanded the most attention. These schemes, however, tend not to deal with the detailed molecular processes which must be involved.

In next Wednesday's Nature New Biology, A. Bennun presents an hypothesis which attempts to relate molecular conformational changes within proteins with the process by which electron flow gives rise to ATP synthesis. He considers that the proteins involved in the energy transduction are coupling factors isolated from either chloroplasts $\left(\mathrm{CF}_{1}\right)$ or mitochondria $\left(\mathrm{F}_{1}\right)$ which show ATPase activity under appropriate conditions. These factors are thought to undergo dynamic stereochemical reactions induced by electron transport which involve charge dependent conformational changes.

Bennun has used kinetic data from chloroplast studies (Bennun and Avron, Biochim. Biophys. Acta, 79, 646 ; 1964) to produce a scheme which involves two stages. The first stage is the formation of a proton dependent electrostatic complex, which is produced, it is argued, when an electron carrier, closely associated with $\mathrm{CF}_{1}$ or $F_{1}$, is reduced.
Because of the change in electric field the redistribution of the electrons within the coupling factors produces new dipolar forms. This complex, however, is not thought to be capable of directly inducing phosphorylation until the second stage, which is brought about by a loss of a proton and the dissipation of the partial charges within the protein. Bennun argues that the disappearance of the dipolar structure of $\mathrm{CF}_{1}$ or $\mathrm{F}_{1}$ leads to the formation of a phosphorylated high energy intermediate which then gives rise to ATP. The formation of these complexes is suggested to occur within the membrane which, as Bennun points out, would tend to result in structural restriction of the conformational changes associated with charge redistribution. Such restrictions could then act as effective energy sources.

Bennun takes his model one step further in attempting to explain the mechanism by which membrane located ATPase catalyses the hydrolysis of ATP and utilizes the energy for active transport of ions. Essentially the reverse process to that already described is thought to occur. The protons released could conceivably conserve their energy by binding to the relevant proteins which may be the ATPase itself or some other membrane protein. This binding could induce conformational changes involving stretching dipoles similar to that suggested for the coupling factors, and may occur as a result of changes in the degree of hydration of the protein. 